University of Nebraska - Lincoln

DigitalCommons@University of Nebraska - Lincoln

Faculty Publications, Department of Psychology

Psychology, Department of

2011

\title{
A Preliminary Investigation of Worry Content in Sexual Minorities
}

Brandon J. Weiss

University of Nebraska-Lincoln

Debra A. Hope

University of Nebraska-Lincoln, dhope1@unl.edu

Follow this and additional works at: https://digitalcommons.unl.edu/psychfacpub

Part of the Gender and Sexuality Commons, Lesbian, Gay, Bisexual, and Transgender Studies Commons, and the Personality and Social Contexts Commons

Weiss, Brandon J. and Hope, Debra A., "A Preliminary Investigation of Worry Content in Sexual Minorities" (2011). Faculty Publications, Department of Psychology. 598.

https://digitalcommons.unl.edu/psychfacpub/598

This Article is brought to you for free and open access by the Psychology, Department of at DigitalCommons@University of Nebraska - Lincoln. It has been accepted for inclusion in Faculty Publications, Department of Psychology by an authorized administrator of DigitalCommons@University of Nebraska - Lincoln. 


\section{A Preliminary Investigation of Worry Content in Sexual Minorities Brandon J. Weiss, Debra A. Hope*}

Weibling Project for the Psycholegal Study and Treatment of Discrimination, University of Nebraska-Lincoln, Lincoln, Nebraska, United States

Abstract: This preliminary study examined the nature of worry content of lesbians, gay men, and bisexual individuals and the relationship between worry related to sexual orientation and mental health. A community sample of 54 individuals identifying as sexual minorities was recruited from two cities in the Great Plains to complete a packet of questionaires, including a modified Worry Domains Questionnaire (WDQ; Tallis, Eysenck, \& Mathews, 1992) with additional items constructed to assess worry over discrimination related to sexual orientation, and participate in a worry induction and verbalization task. The content of self-reported worries was consistent with those reported in prior investigations of worry content, and worry related to sexual orientation was not found to be elevated compared to other topics. However, degree of worry related to sexual orientation was significantly associated with increased negative affect, depressive symptoms, and internalized homophobia and decreased quality of life and positive affect. Implications of these findings, limitations, and future research issues are discussed.

Keywords: Worry, Sexual orientation, Mental health.

According to DSM-IV criteria, the core, defining feature of generalized anxiety disorder (GAD) is pathological worry (American Psychiatric Association, 1994). Worry has been conceptualized as successive, repetitive verbal thoughts and images regarding potential future negative outcomes and their consequences (Borkovec, 1994). According to avoidance theory of worry (Borkovec, Ray, \& Stober, 1998), worry functions as a form of cognitive avoidance against potentially harmful stimuli by disengaging the individual from emotional pain, instead focusing on emotional and cognitive control, thus serving to reduce aversive imagery associated with the stimuli and, ultimately, reducing somatic cues elicited by worry. A variety of studies have suggested that worry is associated with decreased parasympathetic nervous system and increased central nervous system arousal (Thayer, Friedman, \& Borkovec, 1996), feelings of anxiety and muscle tension (Borkovec, Robinson, Pruzinsky, \& DePree, 1983), and predicting anxious arousal (Gana, Martin, \& Canouet, 2001). Other lines of research have focused on the conceptualization of worry as a form of mental problem-solving attempts where worry serves as a coping mechanism for anticipated negative outcomes (Davey, 1994).

\section{Worry Content}

Though few studies have specifically investigated worry content, several investigators over the past two decades have proposed several ways to categorize the phenomenon. Sanderson, DiNardo, Rapee, and Barlow (1990) aggregated worry domains of DSM-III-R diagnosed GAD patients into four categories: family/home, financial, work/school, and illness/health/injury. In a follow-up study, Craske, Rapee, Jackel, and Barlow (1989) classified worry content into the same four categories but included interpersonal relationships in the family/home category and added a miscellaneous category. Surprisingly at the time, miscellaneous worry was one of the highest reported, second only to family/home/interpersonal worries. Roemer, Molina, and Borkovec (1997) replicated and extended

\footnotetext{
The project described was supported in part by a grant to the second author from the Wayne F. Placek Fund of the American Psychological Foundation. The content is solely the responsibility of the authors and does not necessarily represent the official views of the American Psychological Foundation. The authors would like to thank Luis Felipe Morales-Knight, J. Suzanne Singh, Timothy Emge, and Milena Stoyanova for assistance with data collection and Mallory Millard and Abigail Lien for help with data coding. We also thank two anonymous reviewers for their helpful comments on an earlier version of this article. Portions of this work were presented at the 2010 convention for the World Congress of Behavioral and Cognitive Therapies, Boston, Mass., and the 2010 convention for the Society for the Psychological Study of Social Issues, New Orleans, Louisiana.

*Corresponding author at: Department of Psychology, University of Nebraska-Lincoln, Lincoln, Nebraska, United States; dhope1@unl.edu.

Article history: received March 18, 2010; received in revised form September 21, 2010; accepted September 23, 2010.
}

these findings by further classifying miscellaneous worries into five sub-categories: psychological/emotional, minor/routine, future, success/failure, and travel. It is notable that they found a high frequency of reported worry in the minor/routine subcategory, second only to psychological/emotional, of the miscellaneous worry category, as this is consistent with DSM-IV-TR's (American Psychiatric Association, 2000) conceptualization of GAD as frequently involving worry over routine daily activities.

\section{GAD in Sexual Minorities}

Although there are limited data about worry per se in samples of sexual minorities, the available epidemiological data for GAD suggests the extent or nature of worry among sexual minorities might differ from that of heterosexuals. Using data from the National Comorbidity Study (NSC), Gilman et al. (2001) found 12-month prevalence rates of $13.5 \%$ in lesbians versus $4.0 \%$ in heterosexual women and $0.9 \%$ in gay men versus $1.9 \%$ in heterosexual men for GAD. They also found that lesbians and gay men were 3.2 and 2.8, respectively, times more likely than heterosexual women and men to report a lifetime occurrence of GAD. It should also be noted that these data may not be representative of the prevalence of GAD in lesbians and gay men due to a limited sample size $(n=125)$, particularly compared to heterosexual women and men $(n=4,785)$. Additionally, using data from the MacArthur Foundation National Survey of Midlife Development in the United States (MIDUS), Cochran, Sullivan, and Mayes (2003) found a 12-month GAD prevalence rate of $14.7 \%$ for lesbians and bisexual women, with an associated odds ratio of 3.88. Cochran and Mays (2009), using data from the California Quality of Life Survey (Cal-QOL), found 12-month GAD adjusted risk ratios of 1.19 for lesbians and 2.28 for gay men. Also, using data from the National Epidemiologic Survey on Alcohol and Related Conditions (NESARC), Bostwick, Boyd, Hughes, and McCabe (2010) found lifetime prevalence rates of $14.8 \%$ and $22.5 \%$ for lesbian and bisexual women, respectively, versus $10.0 \%$ for heterosexual women and $16.9 \%$ and $11.5 \%$ for gay and bisexual men, respectively, versus $4.8 \%$ for heterosexual men. Sandfort, deGraaf, Bijl, and Schnabel (2001) found somewhat contradictory results using data from the Netherlands Mental Health Survey and Incidence Study (NEMESIS). For gay men, they found a 12-month prevalence rate of $1.2 \%$ versus $0.8 \%$ for heterosexual men, with a corresponding odds ratio of 1.43 , and a lifetime prevalence rate of $3.7 \%$, versus $1.5 \%$ for heterosexual men, with a corresponding odds ratio of 2.88. For lesbians, they found a 12 -month prevalence rate of $0.0 \%^{1}$ versus $1.4 \%$ for heterosexual females, and a lifetime prevalence rate of $2.3 \%$ versus $2.9 \%$ in heterosexual females, with a corresponding odds ratio of 0.84 . Extrapolating from these studies, it appears that 12-month prevalence rates range from $0.0 \%^{1}$ to $14.7 \%$ and from $0.9 \%$ to $1.2 \%$ for lesbians and gay men, respectively. It is interesting that, though many studies provide evidence that GAD is more prevalent among sexual mi- 
norities, prevalence rates differ markedly between samples. Methodology may account for some differences. Although Bostwick et al. (2010) had the highest rates for sexual minorities, their prevalence rates for heterosexuals also tended to be higher than other studies have found. Regardless of the exact rates, however, it is clear that sexual minorities experience GAD more frequently than heterosexuals. What is less clear is whether prevalence is higher for lesbians, gay males, or both, as compared with heterosexual individuals. Also, it is unfortunate that there are no prevalence data for individuals who identify as bisexual, making it unclear how they compare with lesbians, gay men, and heterosexual individuals. Furthermore, these studies provide little information about the nature of the worry experienced by sexual minorities-they simply indicate that they likely experience more pathological worry than heterosexuals.

3. Expression of Anxiety in Sexual Minorities

While prevalence studies have generally shown higher rates of GAD in sexual minorities, this increased prevalence may not be due to the actual presence of the disorder, as suggested by a recent study on social anxiety. Pachankis and Goldfried (2006) found evidence of higher fear of negative evaluation and social interaction in gay males as compared with heterosexual males. The authors offer two possible interpretations for their findings. One interpretation is that their findings are consistent with the minority stress hypothesis (Meyer, 2003), which states that psychological distress is derived from perceived stigma, prejudice, and discrimination experienced as a result of being a member of a low-status minority group (see Herek, 2009; Pachankis, 2007, for reviews of the impact of prejudice and stigma related to sexual orientation). Specifically, they conclude that the higher incidence of social anxiety symptomatology found in their sample was directly related to the participants' sexual minority status, such that certain social situations were particularly salient when the individual perceived possible stigma related to their sexual orientation. Similarly, Pachankis (2007) posits that the salience of stigma related to sexual minority status can lead to preoccupation and vigilance, whichh can lead to negative affective status, such as anxiety and depression. Another possible explanation of their findings is that the greater social anxiety symptomatology experienced by the gay male sample is confounded by the fact that their fears may not actually be "excessive or unreasonable," as per the DSM-IV-TR definition of social anxiety disorder. Their fears may be considered reasonable, perhaps even adaptive, given the societal sexual prejudice they may encounter. Similarly, the higher rates of GAD among sexual minorities found in prevalence studies may not be reflective of a higher presence of the disorder. Rather, it may be indicative of a confound such that if worries experienced by lesbian and gay individuals are mainly focused on content salient to their sexual orientation, then these worries may be considered reasonable given societal prejudice and discrimination.

\section{The Current Study}

While some prevalence data are available, no study to date has explicitly investigated the phenomenology of worry in lesbians and gay men. Thus, the main purpose of the current study was to further elucidate the nature of pathological and non-pathological worry content in a lesbian, gay, and bisexual sample. Worry content was examined to establish whether such worries are related to topics salient to sexual orientation or related to topics commonly reported by individuals with GAD. The relationship between presence/absence of worries related to sexual orientation and rates of pathological worry was also investigated. Also, the relationship between worry related to sexual orientation and mental health was examined. It was predicted that increased worry related to sexual orientation would be associated with decreased mental health. Finally, given findings from prevalence data reviewed above, effects of gender on the above relationships were investigated.

${ }^{1}$ The prevalence rate of $0.0 \%$, reported in Table 2 in Sandfort et al. (2001), indicated that no lesbians in their sample $(n=43$, compared with 3,077 heterosexual females) were diagnosed with GAD.

\section{Method}

5.1. Participants

Participants were 54 individuals recruited as part of a larger study examining anxiety in individuals identifying as gay, lesbian, and bisexual. The sample consisted of 27 women $(50.0 \%)$, 25 men $(46.3 \%)$, and 2 transgender $(3.7 \%)$, and mean age was 32.85 years $(\mathrm{SD}=14.48)$. Self-identified categorical sexual orientation, as determined by an item ["Sexual Orientation (current)"] of the Klein Sexual Orientation Grid (Klein, 1993), was as follows: 20 Gay (37.0\%), 16 Lesbian (29.6\%), 4 Bisexual men (7.4\%) and 3 Bisexual women (5.6\%), 10 Other $(18.5 \% ; 2$ men and 8 women), and 1 woman declined to answer $(1.9 \%)$. Although some individuals did not identify with a standard label, no participant identified as "heterosexual." Participants were well educated, with $94.4 \%$ having completed at least some college. Ethnic distribution was as follows: 46 European Americans $(85.2 \%)$, 2 Hispanics (3.7\%), 1 African American (1.9\%), and 1 Asian American $(1.9 \%)$, and 4 Other/Mixed $(7.4 \%)$.

\subsection{Measures}

\subsubsection{Worry}

5.2.1.1. Penn State Worry Questionnaire (PSWQ; Meyer, Miller, Metzger, \& Borkovec, 1990). The PSWQ is a 16-item self-report measure designed to assess an individual's tendency to and perceived control over worry, not considering specific worry content. It has been studied extensively in clinical, community, and student samples, and the measure's psychometric properties are excellent (Gillis, Haaga, \& Ford, 1995; Molina \& Borkovec, 1994). Specifically, it has good internal consistency and test-retest reliability (Molina \& Borkovec, 1994), and has demonstrated convergent validity (Davey, 1993; Molina \& Borkovec, 1994), discriminant validity (Davey, 1993), and sensitivity to change (Borkovec \& Costello, 1993). Fresco, Mennin, Heimberg, and Turk (2003) suggest that a score of 65 or greater on the PSWQ maximizes sensitivity and specificity in discriminating between individuals with and without GAD. In the current study, Cronbach's alpha was 0.95 .

5.2.1.2. Worry Domains Questionnaire (WDQ; Tallis, Eysenck, \& Mathews, 1992). The WDQ is a 25-item self-report measure assessing the degree of content-specific worry. The domains of contentspecific worry measured by the WDQ cover relationships, lack of confidence, aimless future, work, and finances, each of which are subscales of the WDQ. Particularly notable is that the WDQ assesses both pathological and non-pathological worry. Stober (1998) reports excellent overall internal consistency, adequate to good internal consistency for the subscales, good test-retest reliability, and convergent validity. However, studies of the factor structure of the WDQ are inconsistent (Joorman \& Stober, 1997; van Rijsoort, Emmelkamp, \& Vervaeke, 1999). For the present study, five items were rationally derived, based on knowledge of the sexual minority and sexual stigma literatures (see Herek, 2009, for a review), and added to create an additional subscale to assess worry related to sexual minority status. These items followed the same format as the regular WDQ items. The items were: "I worry that others will find out about my sexual orientation;" "I worry that I will be discriminated against because of my sexual orientation;" "I worry that I will lose friends because of my sexual orientation;" "I worry that my family will reject me because of my sexual orientation;" "I worry that others (who I am not out to) will find out about my sexual orientation." An item analysis was performed on the items constructed to assess worry related to sexual orientation (SO-WDQ). Cronbach's alpha based on these 5 items was 0.92. Inspection of alpha if item deleted did not suggest that dropping any item would improve internal consistency; thus, all 5 items were retained for the final subscale. Inter-item correlations ranged from 0.56 to 0.86 , and subscale total scores ranged from 0 to $20(M=5.02, S D=5.64)$. See Table 1 for correlations between the Sexual Orientation subscale and other subscales of the WDQ. In the current study, Cronbach's alpha for subscales and total score was as follows: 0.85 Relationships, 0.92 Lack of Confidence, 0.89 Aimless Future, 0.81 Work, 0.91 Finances, 0.96 total score without and 0.97 with the Sexual Orientation subscale. 
5.2.2. Anxiety

5.2.2.1. State-Trait Anxiety Inventory-State Form (STAI; Spielberger, Gorsuch, Lushene, Vagg, \& Jacobs, 1983). The STAI is a 20-item selfreport measure assessing current levels of general anxiety. Spielberger et al. (1983) report excellent internal consistency in adult, college, high school, and military recruit samples, and adequate test-retest reliability in high school and college student samples. The STAI has also demonstrated convergent validity (Spielberger et al., 1983) and sensitivity to treatment (Fisher \& Durham, 1999), but failed to discriminate between measures of anxiety and depression (Creamer, Foran, \& Bell, 1995). The STAI was used to assess changes in state anxiety in the worry induction task described below. Cronbach's alpha ranged from 0.92 to 0.97 across administrations (see Section 5.3).

\subsubsection{Mental Health}

5.2.3.1. Quality of Life Inventory (QOLI; Frisch, 1994). The QOLI is a 32-item self-report measure of life satisfaction and positive mental health. Respondents report importance of and satisfaction with 16 different life domains, including health, work, and relationships. The QOLI has demonstrated good internal consistency, test-retest reliability, and convergent and discriminant validity (Frisch, Cornell, Villanueva, \& Retzlaff, 1992), as well as predictive validity and sensitivity to change (Frisch et al., 2005). In the current study, Cronbach's alpha was 0.94 .

5.2.3.2. Beck Depression Inventory-II (BDI-II; Beck, Steer, \& Brown, 1996). The BDI-II is a widely used 21-item self-report inventory of depressive symptoms. The BDI-II has demonstrated excellent psychometric properties, including excellent internal consistency (Cronbach's alpha $=0.92)$, test-retest reliability $(r=0.93)$, and convergent validity ( $r=0.93$ with previous version of the BDI; Beck et al., 1996). In the current study, Cronbach's alpha was 0.89.

5.2.3.3. Internalized Homophobia Scale (IHS; Herek, Cogan, Gillis, \& Glunt, 1998). The HIS is a nine-item self-report measure assessing the degree of one's internalization of society's negative attitudes toward homosexuality. The IHP has demonstrated good internal consistency and convergent validity (Herek et al., 1998; Herek \& Glunt, 1995). IHP scores are positively associated with depressive symptoms and state anxiety, and it is negatively associated with positive affect and self-esteem (Herek, Gillis, \& Cogan, 2009). In the current study, Cronbach's alpha was 0.90 .

5.2.3.4. Positive and Negative Affect Schedule (PANAS; Watson, Clark, $\&$ Tellegen, 1988). The PANAS is a 20 -item self-report measure assessing two distinct dimensions of mood-positive affect (PA) and negative affect (NA), both measured by 10 -item subscales. The validation study reported that both subscales of the PANAS demonstrated good-to-excellent internal consistency, adequate test-retest reliability, excellent convergent and discriminant validity, and a stable factor structure. Other studies have found support for the measure's discriminant validity (Waikar \& Craske, 1997), predictive validity (Watson \& Walker, 1996), and sensitivity to change (McIntyre, Watson, Clark, \& Cross, 1991). Respondents were instructed to indicate how they felt "on average." In the current study, Cronbach's alpha was 0.92 for the NA subscale and 0.88 for the PA subscale.

\subsection{Procedure}

Participants were recruited, as part of a larger study examining anxiety and sexual orientation, via flyers from a variety of locations in the Lincoln and Omaha [e.g., coffee houses, newsletter and meetings of Parents and Friends of Lesbians and Gays (PFLAG), gayfriendly churches, bars and nightclubs with a predominantly lesbian or gay clientele]. Flyers were placed at each location describing the nature of the study and providing contact information for the research team. Upon contacting the research team, interested participants were scheduled for an individual lab session. Participants received $\$ 40$ in exchange for participation in the larger study. The study was approved by the University of Nebraska-Lincoln Institutional Review Board.

\subsubsection{Worry Induction}

Order of tasks completed by participants was counterbalanced. Upon arrival at the lab session and the informed consent procedure, participants completed a battery of questionnaires, including the PSWQ, QOLI, BDI-II, IHS, PANAS, and modified WDQ. Worry was then induced according to procedures described by Molina, Borkovec, Peasley, and Person (1998), slightly modified for the purposes of this study. The following script was used:

"Worry is defined as intrusive thoughts or images about potential future events or catastrophes that produce negative feelings when they occur. For the next few minutes, we would like you to create a worrisome state. Please refer to your list of worrisome topics (WDQ). When I ask you to begin, please close your eyes and worry about your most worrisome topic, in the way that you usually worry about it, but as intensely as you can, until I ask you to stop and to open your eyes. If you normally worry about only one topic at a time, please try to do the same during this period. However, if your thoughts change to another worry topic during this period feel free to allow these thoughts to continue. It is all right to change topics during this period if the changes occur naturally during the worry process."

Participants were allowed to worry for up to five minutes. At every 60-s interval, the participant was prompted to write down what he or she is currently worrying about. Once the worry induction period was completed, participants were asked to verbally detail their worrisome thoughts:

"Now we would like you to worry in your usual way about a topic that is currently most worrisome for you, in the same way as you just did, but this time talking out loud about what's going on in your mind while you are worrying. We hope to find out what worrying is like internally by asking you to do this."

This verbal "stream of consciousness" worry period was digitally recorded for later transcription. Following this task, participants were asked to verbalize five things going well in their life in order to induce a positive mood, or at least bring participants back to their neutral mood prior to worry induction. The STAI was administered prior to and following worry induction, following the verbal worry period, and after positive/neutral mood induction, as a manipulation check. A repeated measures analysis of variance was performed on STAI scores before $(\mathrm{M}=33.19, \mathrm{SD}=11.62)$ and after $(\mathrm{M}=44.17$, $\mathrm{SD}=14.91)$ the worry induction task, after the verbal "stream of consciousness" worry period $(\mathrm{M}=44.98, \mathrm{SD}=15.91)$, and after verbalizing five things going well in their life $(M=36.09, S D=11.70)$ in order to determine the effectiveness of the worry induction. A significant within-subjects effects of time, $F(3,138)=32.53, p<0.001$, partial $\eta^{2}=0.41$, as well as a quadratic trend, $F(1,46)=66.41, p<0.001$, partial $\eta^{2}=0.59$, indicate that state anxiety increased and decreased at the expected time points. See Figure 1 for a graphical depiction of STAI scores.

\subsubsection{Coding}

Participants' verbal, "stream of consciousness" worrying was transcribed and coded by two trained undergraduate research assistants who were blind to the research hypotheses. Research assistants were trained by coding practice transcripts, and any discrepancies were discussed during meetings with the first author and both research assistants until a consensus was reached. Following this training, they coded the actual transcripts.

Worry content was classified into the following categories, derived from worry content categories reported by Craske et al. (1989), Roemer et al. (1997), and the GAD module of the ADIS (Brown, DiNardo, \& Barlow, 1994): Future, Health (Own/Others), Family, Work/ School, Finances, Interpersonal Relationships (Social/Intimate), Routine DailyActivities, and Other. For this study, a sexual orientation category was added that included any thoughts specifically about the individual's sexual orientation including coming out, oth- 
Table 1

Correlations between WDQ subscales.

Subscale 1

1. Relationships $\quad 1.00$

2. Lack of Confidence $\quad 0.75$

$n=51$

3. Aimless Future

4. Work

5. Financial

6. Sexual Orientation

7. WDQ total score
$0.85 \quad 0.77$

$n=53 \quad n=51$

$0.75 \quad 0.73$

$n=52 \quad n=50$

$0.66 \quad 0.56$

$n=51 \quad n=49$

$0.85 \quad 0.63$

$n=51 \quad n=49$

$0.91 \quad 0.87$

$n=48 \quad n=48$

\section{3}

1.00

0.82

$n=53$

0.63

$n=52$

0.75

$n=52$

0.92

$n=48$
4

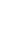

1.00

$0.69 \quad 1.00$

$n=51$

$0.61 \quad 0.51$

$n=51 \quad n=50$

$0.89 \quad 0.80$

$n=48 \quad n=48$
1.00
0.76
$n=46$

Note: All correlations were significant at $p<0.001$.

ers discovering the individual's sexual minority status, or discrimination. The frequency of thoughts verbalized during the worry task was recorded for each category. Interrater reliability for worry content coding ranged from substantial to perfect agreement across worry categories $(\kappa \mathrm{s}=0.69-1.0)$.

6. Results

Prior to testing the hypothesis of this study, all variables were examined for distributional normality, univariate and multivariate outliers, possible data entry errors, and missing data. Frequency analyses were performed to screen the data for accuracy.

\subsection{Gender}

An independent-samples $t$-test compared women and men on worry severity, as measured by the PSWQ. Worry severity significantly differed between female $(\mathrm{M}=39.46, \mathrm{SD}=11.27)$ and male $(\mathrm{M}$ $=47.96, \mathrm{SD}=16.89)$ participants, $t(39.07)=2.10, p=0.04$. Although it is unusual for men to score higher than women on the PSWQ, both scores are within one standard deviation of the community sample normative mean.

A series of $2 \times 2$ chi-square analyses compared female and male participants (transgender participants were included within the group consistent with their current gender presentation) on presence/absence of each worry topic verbalized during the worry task. Worry content from the verbal "stream of consciousness" worrying was dichotomized for each category (i.e., presence/absence of each worry topic). Presence/absence of worry did not differ across gender for any worry topic, $\chi^{2}(1)=0.02-3.48$, $n$ s.

A one-way multivariate analysis of variance (MANOVA) was conducted with gender as the independent variable and the WDQ total score and subscales (Relationships, Lack of Confidence, Aimless Future, Work, Financial, and Sexual Orientation), QOLI, BDI-II, HIS, PANAS-NA, and PANAS-PA as dependent variables. The main effect for gender was not significant, $F(11,21)=0.89$, ns. Follow-up univariate analyses also did not reveal any significant gender differences, $F_{S}=0.001-3.94$, ns.

Given that men and women do not appear to differ on the primary dependent variables of the study, the remainder of the analyses were collapsed across gender.

\subsection{Worry Content}

Mean percentage of worry topic frequencies were calculated. Distribution of worry topic mean percentages were as follows: $26.09 \%$ Finances, 22.26\% Other, 16.30\% Work/School, 10.94\% Interpersonal Relationships, 6.54\% Future, 6.17\% Family, 5.27\% Health (Own/ Others), 3.79\% Routine Daily Activities, and 2.64\% Sexual Orientation. Finances and "other" topics were the most verbalized topics following the worry induction.

\subsubsection{Comparison of Normative Values}

A series of one-sample $t$-tests was performed comparing sample means for the PSWQ and WDQ to community sample normative values reported by Gillis et al. (1995) and Tallis, Davey, and Bond (1994), respectively. Means obtained on the PSWQ did not differ between the current sample $(M=43.39)$ and the community norm $(M$ $=42.20), t(51)=0.58$, ns. Similarly, means obtained on the WDQ did not differ between the current sample $(\mathrm{M}=28.19)$ and the community normative value $(\mathrm{M}=23.10), t(47)=1.67$, ns.

\subsubsection{Sexual Orientation Worry and Mental Health}

First, the relationship between sexual orientation worry, measured by the Sexual Orientation subscale of the WDQ (SO-WDQ), and overall worry severity, measured by the PSWQ, was examined. The correlation between the SO-WDQ and PSWQ was small, $r(50)$ $=0.29, p=0.042$, indicating that worry about sexual orientation was not simply another area in which high worriers experienced worry. Next, zero-order correlations between the SO-WDQ and the QOLI, BDI-II, IHS, PANAS-NA, and PANAS-PA were calculated in order to examine the relationship between sexual orientation worry and quality of life, depressive symptoms, internalized homophobia, negative affect, and positive affect, respectively (see Table 2). Finally, in order to verify that the relationships between the SO-WDQ and mental health variables were not an artifact of overall worry severity, partial correlations were calculated, controlling for PSWQ scores. After controlling for PSWQ scores, the SO-WDQ was positively correlated with the BDI-II $(r=0.55, p=0.001)$, PANAS-NA $(r=0.47, p=0.006)$, and HIS $(r=0.70, p<0.001)$ and negatively correlated with the QOLI $(r=-0.39, p=0.022)$ and PANAS-PA $(r=-0.26, n s)$.

\section{Discussion}

The purpose of the current study was to investigate the worry content of lesbians and gay men. Specifically, worry content was examined to compare whether such sexual minority individuals worry

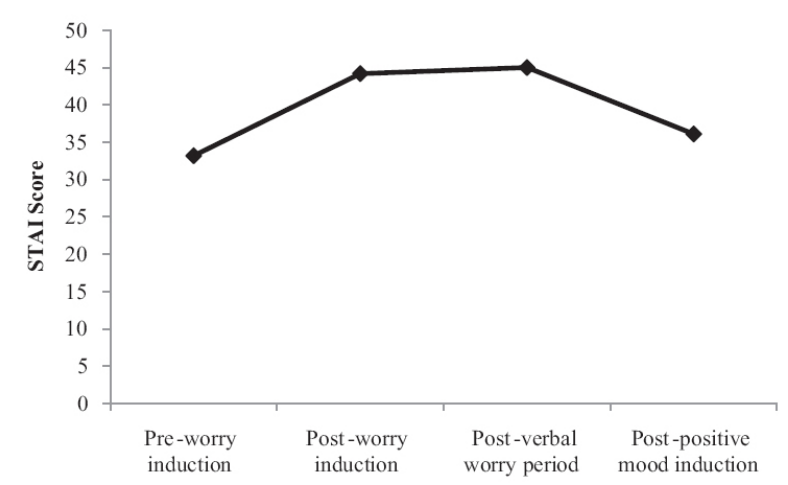

Figure 1. STAI scores pre-worry induction, post-worry induction, post-verbal worry period, and post-positive mood induction. 
Table 2

Zero-order correlations between sexual orientation worry and mental health variables.

$\begin{array}{lllllll}\text { Variable } & 1 & 2 & 3 & 4 & 5 & 6 \\ \text { 1. SO } & 1.002 . & & & & & \\ \text { 2. IHS } & 0.69^{* * *} & 1.00 & & & & \\ & n=47 & & & & & \\ \text { 3. PANAS-PA } & -0.44^{* *} & -0.34^{*} & 1.00 & & & \\ & n=51 & n=47 & & & & \\ \text { 4. PANAS-NA } & 0.52^{* * *} & 0.64^{* * *} & -0.38^{* *} & 1.00 & & \\ & n=51 & n=47 & n=52 & & & \\ \text { 5. QOLI } & -0.36^{*} & -0.40^{* *} & 0.02 & -0.19 & 1.00 & \\ & n=40 & n=41 & n=40 & n=40 & & \\ \text { 6. BDI-II } & 0.59^{* * *} & 0.62^{* * *} & -0.40^{* *} & 0.64^{* * *} & -0.19 & 1.00 \\ & n=50 & n=46 & n=51 & n=51 & n=39 & \end{array}$

Note: $\mathrm{SO}=$ Sexual Orientation subscale of the WDQ; IHS = Internalized Homophobia Scale; PANAS-PA = Positive Affect subscale of the Positive and Negative Affect Schedule; PANAS-NA = Negative Affect subscale of the Positive and Negative Affect Schedule; QOLI = Quality of Life Inventory; BDI-II = Beck Depression Inventory-II.

$* p<0.05$
$* *$
$* * 0.01$

$* * * 0<0.001$.

about content related to their sexual orientation more than topics typically endorsed in prior investigations of worry content, with presumably mostly heterosexual samples. The relationship between worry related to sexual orientation and mental health, as well as effects of gender on worry content, were also examined.

Interestingly, worry severity was higher for male participants than for female participants. This is interesting given the higher prevalence rates of GAD in lesbians (e.g., Gilman et al., 2001). Also, worry related to sexual orientation was not endorsed more than other worry topics. In fact, worry related to sexual orientation was the least endorsed worry topic. Instead, the worry topics most frequently endorsed were finances, work/school, interpersonal relationships, and "other" topics, which is consistent with prior investigations of worry content among general samples of individuals diagnosed with GAD (Craske et al., 1989; Roemer et al., 1997). This suggests that the worry content of lesbians and gay men may not differ from that of heterosexual individuals.

While worry related to sexual orientation was not frequently endorsed, the presence and severity of such worry was strongly related to a number of mental health variables. Increased worry related to sexual orientation related to lower quality of life and positive affect and increased negative affect, depressive symptoms, and internalized homophobia. Also, these relationships remained stable after controlling for variance accounted for by overall worry severity. Thus, the degree of worry related to sexual orientation was found to be highly salient to several aspects of one's overall mental health, including both positive (e.g., quality of life) and negative (e.g., depressive symptoms) aspects of such. Given these findings, it appears that worry related to sexual orientation is important to assess, and the good preliminary psychometric properties of the measure developed for this study will hopefully motivate future research on assessment of this construct, including further refinement of the measure (e.g., enhancing discriminant validity) and, perhaps, construction of a measure through typical scale development procedures (e.g., Spector, 1992). These preliminary data suggest such an endeavor would be worthwhile.

An alternative approach to distinguishing the relationship between sexual orientation worry and mental health variables could have been to examine the correlations after controlling for specific worry content categories (i.e., other subscales of the WDQ) rather than the PSWQ. However, as can be seen by examining item content, worry related to sexual orientation represents a qualitatively distinct area of worry. Also, it makes intuitive sense that individuals who experience elevated levels of worry do so about a number of different topics, and this notion is supported by the correlations among the various subscales of the WDQ. Thus, we felt it was more compelling to investigate the unique relationship between worry related to sexual orientation and mental health variables after controlling for over- all worry severity rather than their relationship after controlling for other worry topics. Put differently, we found it more compelling to ask if these variables were related above and beyond how much an individual worries rather than if he or she was related above and beyond how much an individual worries about other topics.

A number of limitations should be taken into account when interpreting the results of the current study. First, this study did not include a heterosexual comparison group, so it is not possible to compare the worry content using the same procedures in the same study. However, these data do seem comparable to published studies on the worry content for samples not selected for sexual orientation which were presumably largely heterosexual, who did not identify sexual orientation as a frequently identified topic of worry. Published studies of worry content (e.g., Craske et al., 1989; Roemer et al., 1997) using various methodologies have reported fairly consistent worry topics (e.g., routine daily activities, finances) among samples not selected for sexual orientation, and no prior investigations of worry content, unrestricted by preconceived worry categories, suggest that heterosexual individuals worry about topics related to sexual orientation. In considering inclusion of a heterosexual control group in the original design, some methodological problems were encountered. It was difficult to imagine how one might create comparable procedures (e.g., "I (a heterosexual) worry that others will find out about my sexual orientation."), particularly since sexual orientation is not a frequently reported topic of worry for heterosexual individuals.

A second limitation is the small sample size and high education level of the current sample, which may limit generalizability; thus, results should be interpreted with caution. Particular analyses involving the QOLI had somewhat smaller ns because some participants skipped items on this measure due to the double ratings for both satisfaction and importance. Thus, these results should be replicated with a larger sample. A related limitation of the current study is the low number of participants experiencing pathological worry. A sexual minority sample selected for higher levels of worry may produce a richer picture of worry content present in pathological worry. An additional limitation is the possibility that giving participants access to the modified WDQ, including items related to discrimination related to sexual orientation, during the worry induction may have cued participant responses. However, this is unlikely due to the broad number of topics listed on the WDQ and given the low number of participants reporting worries related to sexual orientation. Another limitation is that we were not able to compare lesbian, gay and bisexual individuals separately because of the small number of individuals who identified as bisexual. This is a common problem in research on sexual minorities and in the future we plan to over-recruit for individuals who identify as bisexual. It would be interesting to see if worry content differs among bisexu- 
al individuals, given the possibility that such individuals may experience a different degree of societal stigma and prejudice. The large number who declined to use one of the traditional categories despite indicating same-sex attraction likely reflects the changing use of labels in the sexual minority community (e.g., Savin-Williams, 2009). A final limitation is that the data were collected from a convenience sample that may not be representative of the larger sexual minority population. While efforts were made to sample a wide range of the lesbian and gay community, it is possible that certain members were more likely to participate. For example, the high percentage of worries reported related to finances may be partially due to individuals with financial difficulties having been more likely to participate in the study, given the compensation for participation.

Despite these limitations, the current study has a number of strengths. First, the study utilized a community sample with a mean age in the early 30s and an age range of 19-66 years. Second, standard measures and an established worry induction procedure were used, making the study comparable to previous studies of worry. Third, the study was conducted in an area of the country without legal protections for sexual minorities and without a large open gay community such as found in some urban areas, indicating that results may generalize to similar communities that tend to be under studied.

This is the first study explicitly examining the phenomenology of worry content in sexual minorities and the relation of worry related to sexual orienation and mental health. Sexual minorities are underrepresented in psychological research, particularly in how their minority status could potentially alter their experience and expression of both normal and abnormal processes, such as pathological and nonpathological worry content. Thus, it is hoped that this study could act as an impetus to future studies examining how one's status as a sexual minority can affect such processes, including large national and multisite longitudinal studies of mental health in sexual minorities that take into account cohort and location effects. The results of this study imply that worry about discrimination due to sexual orientation (e.g., being "outed") may be associated with poorer mental health. Given the correlational nature of the study, it is impossible to determine whether individuals with poorer mental health are more likely to worry about their sexual minority status or if this worry is an important implication of the adverse cosequences of sexual prejudice, including anti-gay social policy and climates perceived as non-affirming of sexual minorities. This is an empirical question that should be addressed in future research.

\section{References}

American Psychiatric Association. (1994). Diagnostic and Statistical Manual of Mental Disorders (4 $4^{\text {th }}$ ed.). Washington, D.C.: Author.

American Psychiatric Association. (2000). Diagnostic and Statistical Manual of Mental Disorders ( $4^{\text {th }}$ ed., text revision). Washington, D.C.: Author.

Beck, A.T., Steer, R.A., \& Brown, G.K. (1996). Beck Depression Inventory Manual ( $2^{\text {nd }}$ ed.). San Antonio: Psychological Corporation.

Borkovec, T.D. (1994). The nature, functions, and origins of worry. In: G.C.L. Davey, \& F. Tallis (Eds.), Worrying: Perspectives on Theory, Assessment, and Treatment (pp. 5-33). Chichester, England: Wiley.

Borkovec, T.D., \& Costello, E. (1993). Efficacy of applied relaxation and cognitive-behavioral therapy in the treatment of generalized anxiety disorder. Journal of Consulting and Clinical Psychology 61: 611-619.

Borkovec, T.D., Ray, W.J., \& Stober, J. (1998). Worry: a cognitive phenomenon intimately linked to affective, physiological and interpersonal behavioral processes. Cognitive Therapy and Research 8:561-576.

Borkovec, T.D., Robinson, E., Pruzinsky, T., \& DePree, J. (1983). Preliminary exploration of worry: some characteristics and processes. Behaviour Research and Therapy 21: 9-16.

Bostwick, W.B., Boyd, C.J., Hughes, T.L., \& McCabe, S.E. (2010). Dimensions of sexual orientation and the prevalence of mood and anxiety disorders in the United States. American Journal of Public Health 100: 468-475.
Brown, T.A., DiNardo, P.A., \& Barlow, D.H. (1994). Anxiety Disorders Interview Schedule for DSM-IV (ADIS-IV). San Antonio, TX: Psychological Corporation.

Cochran, S.D., \& Mays, V.M. (2009). Burden of psychiatric morbidity among lesbian, gay, and bisexual individuals in the California Quality of Life Survey. Journal of Abnormal Psychology 118: 647-658.

Cochran, S.D., Sullivan, J.G., \& Mayes, V.M. (2003). Prevalence of mental disorders, psychological distress, and mental health services use among lesbian, gay, and bisexual adults in the United States. Journal of Consulting and Clinical Psychology 71: 53-61.

Craske, M.G., Rapee, R.M., Jackel, L., \& Barlow, D.H. (1989). Qualitative dimensions of worry in DSM-III-R generalized anxiety disorder subjects and nonanxious controls. Behaviour Research and Therapy 27: 397-402.

Creamer, M., Foran, J., \& Bell, R. (1995). The Beck Anxiety Inventory in a non-clinical sample. Behaviour Research and Therapy 33: 477-485.

Davey, G.C.L. (1993). A comparison of three worry questionnaires. Behaviour Research and Therapy 31: 51-56.

Davey, G.C.L. (1994). Pathological worrying as exacerbated problem-solving. In: G.C.L. Davey, \& F. Tallis (Eds.), Worrying: Perspectives on Theory, Assessment, and Treatment (pp. 35-59). Chichester, England: Wiley.

Fisher, P.L., \& Durham, R.C. (1999). Recovery rates in generalized anxiety disorder following psychological therapy: an analysis of significant change in the STAI-T across outcome studies since 1990. Psychological Medicine 29: 1,425-1,434.

Fresco, D.M., Mennin, D.S., Heimberg, R.G., \& Turk, C.L. (2003). Using the Penn State Worry Questionnaire to identify individuals with generalized anxiety disorder: a receiver operating characteristic analysis. Journal of Behavior Therapy and Experimental Psychiatry 34(3-4): 283-291.

Frisch, M.B. (1994). Quality of Life Inventory. Minneapolis, Minn.: Pearson Assessments.

Frisch, M.B., Clark, M.P., Rouse, S.V., Rudd, M.D., Paweleck, J.K., Greenstone, A., et al. (2005). Predictive and treatment validity of life satisfaction and the Quality of Life Inventory. Assessment 12: 66-78.

Frisch, M.B., Cornell, J., Villanueva, M., \& Retzlaff, P. (1992). Clinical validation of the Quality of Life Inventory: a measure of life satisfaction for use in treatment planning and outcome assessment. Psychological Assessment 4: 92-101.

Gana, K., Martin, B., \& Canouet, M.D. (2001). Worry and anxiety: is there a causal relationship? Psychopathology 34(5): 221-229.

Gillis, M.M., Haaga, D.A.F., \& Ford, G.T. (1995). Normative values for the Beck Anxiety Inventory, Fear Questionnaire Penn State Worry Questionnaire, and Social Phobia and Anxiety Inventory. Psychological Assessment 7: 450-455.

Gilman, S.E., Cochran, S.D., Mays, V.M., Hughes, M., Ostrow, D., \& Kessler, R.C. (2001). Risk of psychiatric disorders among individuals reporting same-sex sexual partners in the National Comorbidity Study. American Journal of Public Health 91(6): 933-939.

Herek, G.M. (2009). Sexual stigma and sexual prejudice in the United States: a conceptual framework. In: D.A. Hope (Ed.), Contemporary Perspectives on Lesbian, Gay, and Bisexual Identities: the $54^{\text {th }}$ Nebraska Symposium on Motivation (pp. 65-111). New York: Springer.

Herek, G.M., Cogan, J.C., Gillis, J.R., \& Glunt, E.K. (1998). Correlates of internalized homophobia in a community sample of lesbians and gay men. Journal of the Gay and Lesbian Medical Association 2: 17-25.

Herek, G.M., Gillis, J.R., \& Cogan, J.C. (2009). Internalized stigma among sexual minority adolescents: insights from a social psychological perspective. Journal of Counseling Psychology 56: 32-43.

Herek, G.M., \& Glunt, E.K. (1995). Identity and community among gay and bisexual men in the AIDS era: preliminary findings from the Sacramento Men's Health Study. In: G.M. Herek, \& B. Greene (Eds.), AIDS, Identity, and Community: The HIV Epidemic and Lesbians and Gay Men (pp. 55-84). Thousand Oaks, Calif.: Sage.

Joorman, J., \& Stober, J. (1997). Measuring facets of worry: a LISREL analysis of the Worry Domains Questionnaire. Personality and Individual Differences 23: 827-837. 
Klein, F. (1993). The Bisexual Option (2 ${ }^{\text {nd }}$ ed.). Binghamton, N.Y.: Haworth.

McIntyre, C.W., Watson, D., Clark, L.A., \& Cross, S.A. (1991). The effect of induced social interaction on positive and negative affect. Bulletin of the Psychonomic Society 29: 67-70.

Meyer, I.H. (2003). Prejudice, social stress, and mental health in lesbian, gay, and bisexual populations: conceptual issues and research evidence. Psychological Bulletin 129: 674-697.

Meyer, T.J., Miller, M.L., Metzger, R.L., \& Borkovec, T.D. (1990). Development and validity of the Penn State Worry Scale. Behaviour Research and Therapy 28: 487-495.

Molina, S., \& Borkovec, T.D. (1994). The Penn State Worry Questionnaire: psychometric properties and associated characteristics. In: G.C.L. Davey, \& F. Tallis (Eds.), Worrying: Psychological Perspectives on Theory, Assessment, and Treatment (pp.265-283). New York: Wiley.

Molina, S., Borkovec, T.D., Peasley, C., \& Person, D. (1998). Content analysis of worrisome streams of consciousness in anxious and dysphoric participants. Cognitive Therapy and Research 22: 109-123.

Pachankis, J.E. (2007). The psychological implications of concealing a stigma: a cognitive-affective-behavioral model. Psychological Bulletin 133: 328-345.

Pachankis, J.E., \& Goldfried, M.R. (2006). Social anxiety in young gay men. Journal of Anxiety Disorders 20: 996-1,015.

Roemer, L., Molina, S., \& Borkovec, T.D. (1997). An investigation of worry content among generally anxious individuals. Journal of Nervous and Mental Disease 185: 314-319.

Sanderson, W.C., DiNardo, P.A., Rapee, R.M., \& Barlow, D.H. (1990). A description of patients diagnosed with DSM-III revised generalized anxiety disorder. Journal of Nervous and Mental Disease 178: 588-591.

Sandfort, T.G.M., deGraaf, R., Bijl, R.V., \& Schnabel, P. (2001). Samesex sexual behavior and psychiatric disorders. Archives of General Psychiatry 58: 85-91.

Savin-Williams, R.C. (2009). How many gays are there? It depends.
In: D.A. Hope (Ed.), Contemporary Perspectives on Lesbian, Gay, and Bisexual Identities: the $54^{\text {th }}$ Nebraska Symposium on Motivation (pp. 5-42). New York: Springer.

Spector, P.E. (1992). Summated rating scale construction: an introduction. In: M.S. Lewis-Bexk (Ed.), Quantitative Applications in the Social Sciences. Newbury Park, Calif.: Sage.

Spielberger, C.D., Gorsuch, R.L., Lushene, R., Vagg, P.R., \& Jacobs, G.A. (1983). Manual for the State-Trait Anxiety Inventory (Form Y). Palo Alto, Calif.: Mind Garden.

Stober, J. (1998). Reliability and validity of two widely-used worry questionnaires: self-report and self-peer convergence. Personality and Individual Differences 24: 887-890.

Tallis, F., Davey, G.C.L., \& Bond, A. (1994). The Worry Domains Questionnaire. In: F. Tallis, \& G.C.L. Davey (Eds.), Worrying: Perspectives on Theory, Assessment, and Treatment (pp. 285-297). New York: Wiley.

Tallis, F., Eysenck, M.W., \& Mathews, A. (1992). A questionnaire for the measurement of non-pathological worry. Personality and Individual Differences 13: 161-168.

Thayer, J.F., Friedman, B.H., \& Borkovec, T.D. (1996). Autonomic characteristics of generalized anxiety disorder and worry. Biolog ical Psychiatry 39: 255-266.

Van Rijsoort, S., Emmelkamp, P., \& Vervaeke, G. (1999). The Penn State Worry Questionnaire and the Worry Domains Questionnaire: structure, reliability, and validity. Clinical Psychology and Psychotherapy 6: 297-307.

Waikar, S.V., \& Craske, M.G. (1997). Cognitive correlates of anxious and depressive symptomatology: an examination of the helplessness/hopelessness model. Journal of Anxiety Disorders 11: 1-16.

Watson, D., Clark, L.A., \& Tellegen, A. (1988). Development and validation of brief measures of positive and negative affect: the PANAS scales. Journal of Personality and Social Psychology 54: 1,063-1,070. Watson, D., \& Walker, L.M. (1996). The long-term stability and predictive validity of trait measures of affect. Journal of Personality and Social Psychology 70: 567-577. 